\title{
Removal of Turbidity and Sludge Production from Industrial Process Wastewater Treatment by a Rejection of Steel Rich in $\mathrm{FeCl}_{3}$ (SIWW)
}

\author{
Malika Kastali ${ }^{1}$, Latifa Mouhir ${ }^{1}$, Mohamed Chatoui ${ }^{1}$, Salah Souabi ${ }^{1}$, Abdelkader Anouzla ${ }^{1, *}$ (i) \\ 1 Laboratory of Process Engineering and Environment, Faculty of Science and Technology Mohammedia, Hassan II \\ University of Casablanca, Morocco; partenariat20@gmail.com (M.K.), is29702020@gmail.com (L.M.), \\ santescolaire.ss@gmail.com (M.C), salah.souabi@gmail.com(S.S.); \\ * Correspondence: aanouzla@gmail.com;
}

Scopus Author ID 25959822200

Received: 2.01.2021; Revised: 1.02.2021; Accepted: 4.02.2021; Published: 9.02.2021

\begin{abstract}
The pollution of industrial wastewater in Morocco poses serious problems for the environment. These effluents must be treated before discharge into the receiving environment. In this work, industrial steel wastewater (SIWW), rich in $\mathrm{FeCl}_{3} 30 \%$, was used as a useful and profitable coagulant and as liquid waste to be recovered in the treatment of wastewater. The coagulationflocculation process using ferric chloride was studied using the Jar Test technique. The results obtained using $\mathrm{FeCl}_{3} 30 \%$ (SIWW) have shown that the $\mathrm{pH}$ has a very significant effect on reducing turbidity for three types of polluting loads: high load, medium load. The reduction of turbidity and sludge production by $\mathrm{FeCl}_{3} 30 \%$ (SIWW) is a function of the pollutant load of the wastewater to be treated and the $\mathrm{pH}$. The higher the pollution load, the higher the optimal concentration of $\mathrm{FeCl}_{3} 30 \%$ (SIWW). The $30 \% \mathrm{FeCl}_{3}$ made it possible to remove more than $95 \%$ of the turbidity at a high load. In conclusion, industrial rejection rich in $\mathrm{FeCl}_{3}$ could be used to reduce the turbidity of industrial refinery wastewater considerably.
\end{abstract}

Keywords: vegetable oil refinery wastewater; $\mathrm{FeCl}_{3} 30 \%$ (SIWW); coagulation floculation; turbidity; sludge production.

(C) 2021 by the authors. This article is an open-access article distributed under the terms and conditions of the Creative Commons Attribution (CC BY) license (https://creativecommons.org/licenses/by/4.0/).

\section{Introduction}

There are many causes of water pollution: industrial waste, urban and industrial wastewater, chemical fertilizers, urban and industrial development, etc. Wastewater from all activities, whether domestic or industrial agricultural effluents, contains unwanted pollutants, which can be rich in toxic pollutants $[1,2]$.

In this context, a constant effort must be made to protect water resources[3]. Legislation relating to liquid industrial effluents is becoming increasingly strict in both developed and developing countries. This requires the treatment of all wastewater before it is released into the environment. Currently, water policy considers climate change and the protection of surface water, groundwater, and coastal water [1-4]. The protection of water sources from pollution as well as the recycling of treated water responds to technological developments, environmental as well as significant economic, represent the major interests targeted by the Moroccan government in recent years because of the problems facing the world such as global 
warming, lack of precipitations, depletion of fossil fuel resources and the increase in their prices.

The vegetable oil refinery industry is an important sector at the national level in Morocco. It is significant water consumption and consequently a large wastewater producer. Lesieur-Cristal is the first producer of vegetable oil in Morocco. The company has two processing units in Morocco, located in Roche Noire and Ain-Harrouda. The company operates under three segments: oilseed milling, oil refining process, and soap making process. It produces olive oils and other edible oils, as well as various soaps, such as body and laundry soaps. As a matter of fact, with the aim to protect the environment, the company has constructed a treatment station for the waste generated during the process of oil refining. This wastewater results in environmental pollution, especially when the pollution status exceeds an acceptable level [5-7]. Its characteristics depend largely on the type of oil processed and the process implemented that is high in COD, oil and grease, and sulfate and phosphate content, resulting in high inorganic and organic wastewater [5, 8].

Wastewater must be treated to contribute to a cleaner environment. Several methods have been used to treat refinery wastewater, secondary and synthetic wastewater from petroleum refineries, including adsorption [3,9], electrocoagulation [10], biological processes [11], physical-chemical treatment [12], membrane processes [13], coagulation-flocculation [5, 7], electrochemical treatment [14], sequential batch reactor (SBR) combined with physicochemical treatment [15]. The high performance, the small footprint of the installations, and the low consumption of reagents make flotation methods alone or combined with biological treatment a performance allowing a significant reduction of pollution. In addition, Bharat in situ. (2018) [16] studied the degradation of organic pollutants in wastewater from vegetable oil refineries by hydrodynamic cavitation: a process intensification technique. The authors have shown that the technique is effective in reducing the pollution of effluents considerably. This treatment of wastewater is based on the removal of unwanted components so that to dump less polluting discharge into the environment at the end. This result can be achieved through physical, chemical, and biological ways. Physical treatment methods such as screening, sedimentation, and skimming help remove floating objects, grit, oil, and grease [1].

The chemical treatment method, represented by precipitation, $\mathrm{pH}$ adjustment, coagulation, oxidation, and reduction, removed the colloidal impurities [8, 17].

When activated sludge, the settling phase is allowed to settle under a steady flow getting into the basin where no aeration and mixing takes place. This is a critical phase since when the solids take too long to settle, some sludge can be drawn subsequent decant phase and can lead to the effluent's quality degradation [1]. Studies of the settling ability of the activated sludge have been carried out extensively [8,18]. This process's complexity arises from the influence of many parameters, such as size, fractal dimension, and porosity of flocs, suspension solid, carrier fluid viscosity, temperature, nutrient and oxygen concentrations, $\mathrm{pH}$, conductivity, and hydrodynamics of the system [5].

Shuo Wang [14] used $\mathrm{FeCl}_{3}$ and cationic polyacrylamide for the conditioning of excess sludge from a wastewater treatment plant (STEP) and the dewatering performance by different chemical conditioners was studied. Experimental results have shown that $\mathrm{FeCl}_{3}$ can produce small and concentrated mud particles.

The coagulation-flocculation process is widely used for the treatment of wastewater. Many coagulants are commonly used for treatment, such as aluminum sulfate (alum), ferrous sulfate, ferric chloride [5], and polyaluminium chloride (PAC) [8]. Nattawin et al. (2019) [19] 
studied oily wastewater treatment by the combination of flotation and induced air coagulation or modified induced air flotation.

Industrial discharges loaded with toxic materials in the world pose serious problems [1] for rural communities since the techniques for treating these discharges are expensive and present a heavy burden for developing countries for most companies.

How to get rid of toxic industrial wastewater since these discharges have a considerable impact on the environment? The question deserves to be asked since the regulations have not yet been applied to minimize the environment's impact. This environmental, technical, but above all, financial burden, linked to industrial waste treatment, will constitute a challenge for most companies that do not have the possibility of financing a project for treating industrial wastewater. Coagulation-flocculation treatment is an effective technique for reducing industrial waste pollution by various coagulants, particularly $\mathrm{FeCl}_{3}$.

The industrial steel company uses a significant amount of $\mathrm{HCl}$ acid in the manufacturing process, which produces a release highly charged with $\mathrm{FeCl}_{3}$, which must be used in wastewater treatment in Morocco. It should be noted that $100 \mathrm{~m} 3$ of wastewater discharged rich in $\mathrm{FeCl} 3$ at $30 \%$ could be recovered and valued. Up to this point, the company has not yet thought of recycling the wastewater treatment. Our work is an essential element to attract the attention of the leaders of society, the commune of Casablanca, other urban communes, and private companies.

In this work, the $\mathrm{FeCl}_{3}$ used is an industrial effluent rich in ferric chloride (SIWW) produced by a steel company that operates 24/24 and 6/7. At the industrial unit level, a significant amount of $\mathrm{HCl}$ acid is used in the manufacturing process, which produces a rejection heavily loaded with $\mathrm{FeCl} 3$, which can be used in the treatment of wastewater as a coagulant. This study constitutes an essential element allowing to attract the managers of the company's managers, the municipality of Casablanca and private companies for such a valuation.

It should be recalled that the question of the cost of treatment poses a problem due to the insufficient funds for the realization of a de-pollution technique. Coagulation-flocculation requires optimization of the coagulant concentration, which results in a good agglomeration of the particles making it possible to destabilize the colloids and subsequently a good settling of the pollutants [20].

The present work studied reducing the turbidity of the pollution of refinery process wastewater and sludge production during treatment by an industrial rejection of iron and steel industry rich in $\mathrm{FeCl}_{3} 30 \%$ (SIWW). This makes it possible to prevent the discharge rich's valorization in $\mathrm{FeCl}_{3}$ (SIWW) while monitoring the production of the sludges during the treatment by coagulation-flocculation. Thus, the use of the discharge can be prevented for the de-pollution of agro-food discharges in general, and, in particular, the discharges of wastewater produced by Lesieur Ain Harrouda Casablanca.

\section{Materials and Methods}

\subsection{Production process.}

The refinery uses chemical and physical methods to refine oils (rapeseed, sunflower, soybean, palm, and hydrogenated). On average, the refinery generates $1200 \mathrm{~m}^{3}$ of wastewater daily, which includes acid wastewater $\left(80-270 \mathrm{~m}^{3} \cdot \mathrm{d}^{-1}\right)$ and process wastewater $(570-1000$ $\left.\mathrm{m}^{3} \cdot \mathrm{d}^{-1}\right)$. The acid wastewater is that stream coming from the soapstock splitting process, 
whereas the process wastewater is that stream originating from all the factory's process installations and equipment (Figure 1).

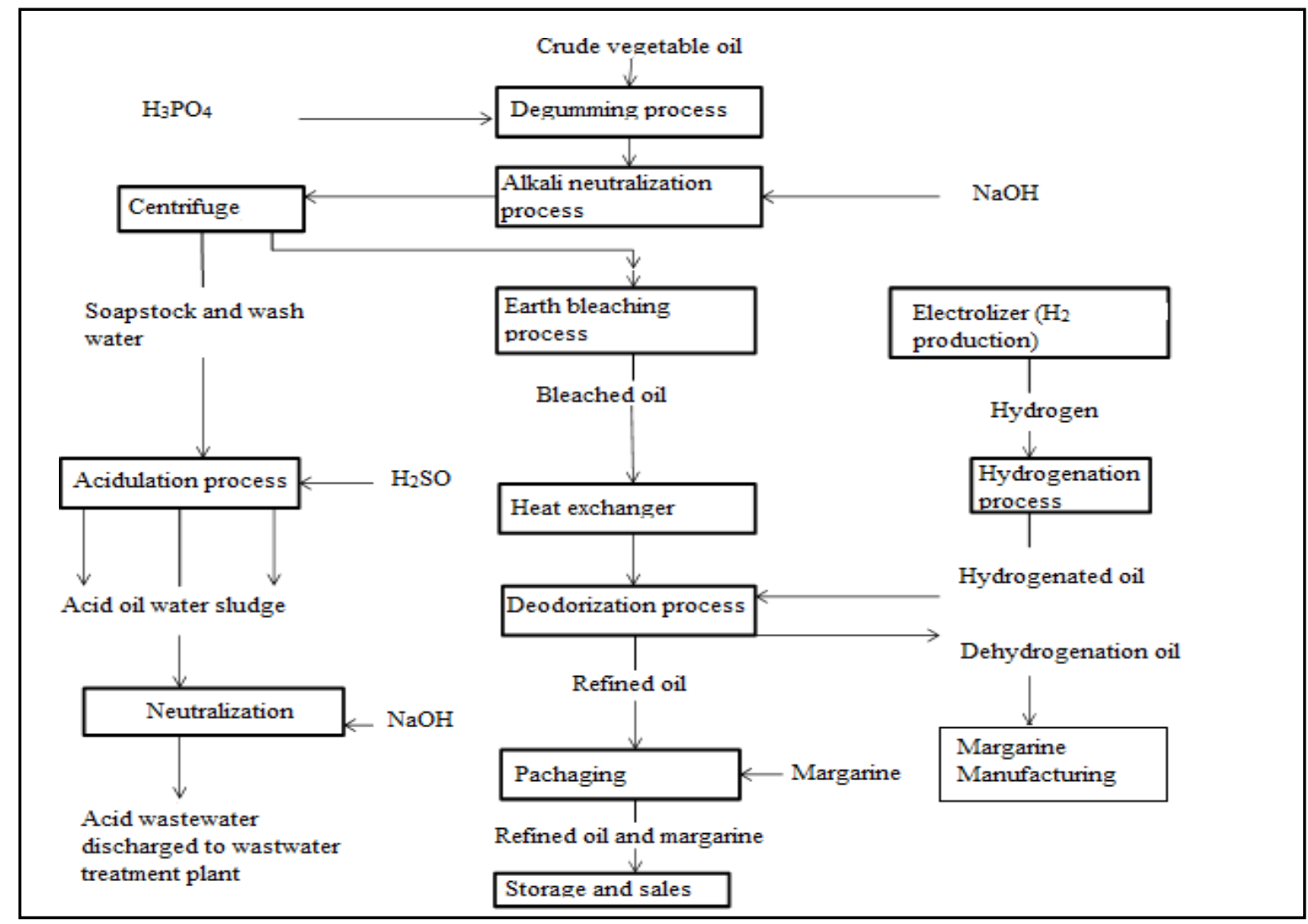

Figure 1. Simplified schematic diagram of refinery vegetable oils processes: the source of vegetable oil refinery wastewater (acid and process wastewater).

Industrial wastewater samples for this study were collected from the leading agroindustrial companies (Lesieur-Cristal). In Africa, the oil refinery is one of the leading agroindustrial companies (Lesieur-Cristal). The company has two processing units in Morocco, located in the region of Casablanca. The company operates in: oilseed milling, oil refining process, and soap making process. It produces olive oils and other edible oils, as well as various soaps. On average, the company generates around 1,200 $\mathrm{m} 3$ of wastewater per day, in particular acidic wastewater (80-270 m3.day-1) and process wastewater (570-1000 m3.day-1).

The process wastewater is that stream originating from all the factory's process installations and equipment. Figure 1 shows the diagram of VOR processes and the source of acid and process wastewater.

The investigations were carried out on freshly collected untreated wastewater samples coming from the company. The process wastewater is a mixture of refinery, soap, and glycerin wastewater. Acidic and process wastewaters are the influents that enter into the wastewater treatment plant.

\subsection{Wastewater treatment plant.}

The wastewater treatment plant flow diagram is shown in Figure 2. To protect the environment, the company has constructed a treatment station for the waste generated during the process of oil refining. This treatment of wastewater is based on removing unwanted 
components to throw less polluting discharge into the environment at the end. This result can be achieved through physical, chemical, and biological ways.

Pre-treatment, coagulation $\left(\mathrm{FeCl}_{3}\right)$, flocculation, and dissolved air flotation methods are the primary steps, while sequencing batch reactors (SBR) systems are the second step during the wastewater treatment process.

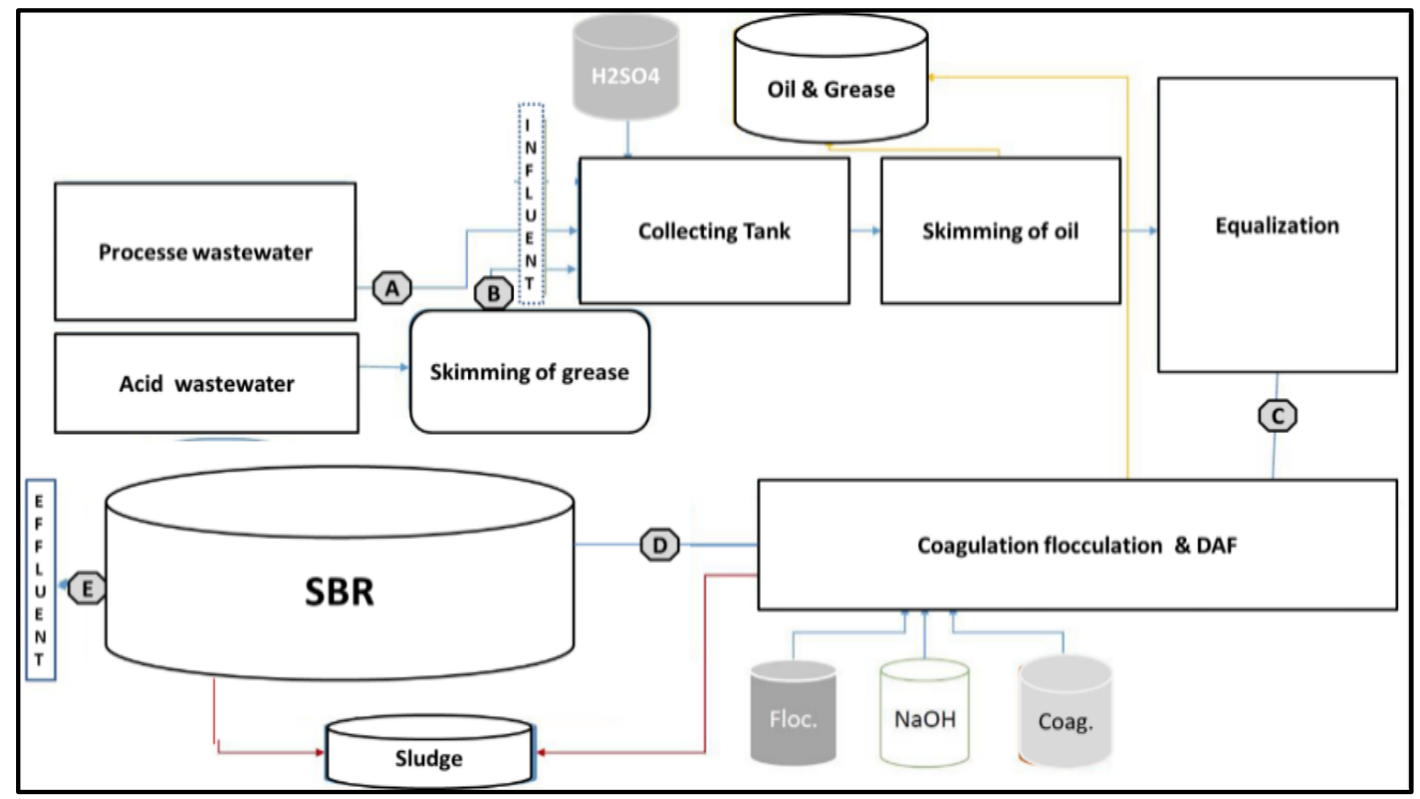

Figure 2. Wastewater treatment of Lesieur by coagulation-flocculation combined with SBR.

\subsection{Sampling procedures and analytical parameters.}

Samples were taken from the company Lesieur Ain Harrouda Casablanca at the rate of 5 liters per hour during the company's operating time ( 8 hours / 24 hours), which made it possible to obtain a composite sample of 40 liters. This allows a representative characterization of the effluent to be obtained. Wastewater was stored at $4{ }^{\circ} \mathrm{C}$ and was equilibrated to room temperature before use.

The samples were stored under $4{ }^{\circ} \mathrm{C}$ temperature before being analyzed. All the samples were analyzed to determine all the physicochemical parameters following the procedure established in the standard methods to examine water and wastewater (AFNOR 1999 STANDARD).

The $\mathrm{pH}$ and temperature of all samples were measured in situ. The temperature was measured with an ASTM 5C thermometer. The $\mathrm{pH}$ was measured according to the NF T 90008 February 2001 (T 90-008). OD was measured with a dissolved oxygen probe HI 9143. The Chemical Oxygen Demand (COD) was performed according to standard AFNOR in force (NF T90-101 February 2001 (T90-101)). Measuring the biological oxygen demand after 5 days (BOD5) was facilitated by the use of the manometric method ((NF EN 1899 May 1998) (T90103)). The turbidity was measured according to standard NF EN ISO 7027 March 2000 (T 90033). The determination of suspended matter was conducted by the centrifugation method according to standard (NF T 90-105 January 1997 (T 90-105)). The oil and grease were measured according to standard method 1164, EPA. The surfactant concentration was analyzed using solvent extraction and quantitative spectrophotometric determination with the ethyl violet method. Phenolic compounds were determined by the colorimetric method using the Folin-Ciocalteu. 


\subsection{Optimization of coagulant dose and $\mathrm{pH}$ in the coagulation process.}

A laboratory-scale evaluation of coagulation and flocculation was performed using the test jar technique. The experimental method is composed of three steps: a rapid mixture of wastewater containing reactive flocculation coagulation reagents of $160 \mathrm{rpm}$ for $10 \mathrm{~min}$, followed by slow stirring at $30 \mathrm{rpm}$ for 20 minutes, and then a final decantation step for $30 \mathrm{~min}$ and 24 hours. The coagulation-flocculation was performed with the previously optimized and determined operating parameters.

Six polyethylene beakers with a volume of 1 liter were used to examine the different doses of coagulant. The samples to be tested were deeply agitated to suspend the settled solids. The appropriate volume of the sample was transferred to the corresponding test beakers. To study the optimal dose of coagulant, the wastewater solution's $\mathrm{pH}$ is maintained at the optimum value and variable doses of the $\mathrm{FeCl}_{3} 30 \%$ (SIWW). After 30 minutes and 24 hours of decantation, the supernatant was removed for analysis. To assess the efficiency of the $\mathrm{FeCl}_{3}$ $30 \%$ (SIWW) on wastewater treatment, the following characteristics are determined: turbidity and sludge production. The elimination efficiency $(\mathrm{R})$ was calculated by the following equation:

$$
\% \text { Turbidity }=100 *\left(\mathrm{C}_{\mathrm{i}}-\mathrm{C}_{\mathrm{f}}\right) / \mathrm{C}_{\mathrm{f}}
$$

where $\mathrm{C}_{0}$ and $\mathrm{C}_{\mathrm{F}}$ are respectively the initial and final values of the studied parameters.

\section{Results and Discussion}

\subsection{Results.}

3.1.1. Physicochemical characteristic of process wastewater.

Indeed, the study's discharges come from an industrial refinery unit that treats wastewater by coagulation-flocculation with $\mathrm{FeCl}_{3}$ followed by treatment with $\mathrm{SBR}$. The sludge produced by coagulation with $\mathrm{FeCl}_{3}$ during treatment is rich in oils and fats. A more detailed study makes it possible to avoid production in quantity and quality. Table 1 illustrates the physicochemical characteristics of the analyzed wastewater

Table 1. Physicochemical characteristics of the wastewater used for the study.

\begin{tabular}{|c|c|c|c|}
\hline Parameter & Maximum & Average & Minimum \\
\hline $\mathrm{pH}$ & 10 & 9.6 & 9.3 \\
\hline TSS mg/l & 10200 & 7321 & 5420 \\
\hline COD mg/l & 53600 & 49192 & 43500 \\
\hline BOD5 $\mathrm{mg} / \mathrm{l}$ & 16000 & 11007 & 6800 \\
\hline Oil and greases $\mathrm{mg} / \mathrm{l}$ & 6650 & 6123 & 4880 \\
\hline phenol mg/l & 58.3 & 46.3 & 33.4 \\
\hline Surfactant $\mathrm{mg} / \mathrm{l}$ & 17.6 & 11.75 & 6.5 \\
\hline COD/DBO5/ & 3,4 & 4,35 & 6,7 \\
\hline
\end{tabular}

Due to industrial development in developing countries, particularly the various industrial uses of oils and fats, pollution of our environment is becoming an increasingly severe problem. It is therefore essential to find an effective method to remove oils and greases from polluted waters. Indeed, the treatment of wastewater by more advanced techniques makes it possible to produce a large quantity of sludge, which must be treated before discharge into public landfills or recovered in agriculture. 


\subsubsection{Variation of pollutant loads of fats and oils and TSS.}

The relationship between TSS and fat concentration is shown in Figure 3.

The results obtained show a good correlation between TSS and the fats and oils in the wastewater studied. The concentration of oils and fats varies in the same direction as the TSS, which correlates with the two parameters' pollutant loads. A high concentration of total solids may reduce the effectiveness of the wastewater treatment plant. The estimate of total suspended solids (TSS) is very important to select the treatment process. The direct measurement of TSS is relatively more expensive and longer than turbidity. Numerous surveys show that turbidity is related to suspended sediments [21]. Turbidity can be caused by the presence of suspended solids, such as inorganic matter and organic matter of all forms. The relationship between TSS and turbidity is affected by the density, size, and shape of particles

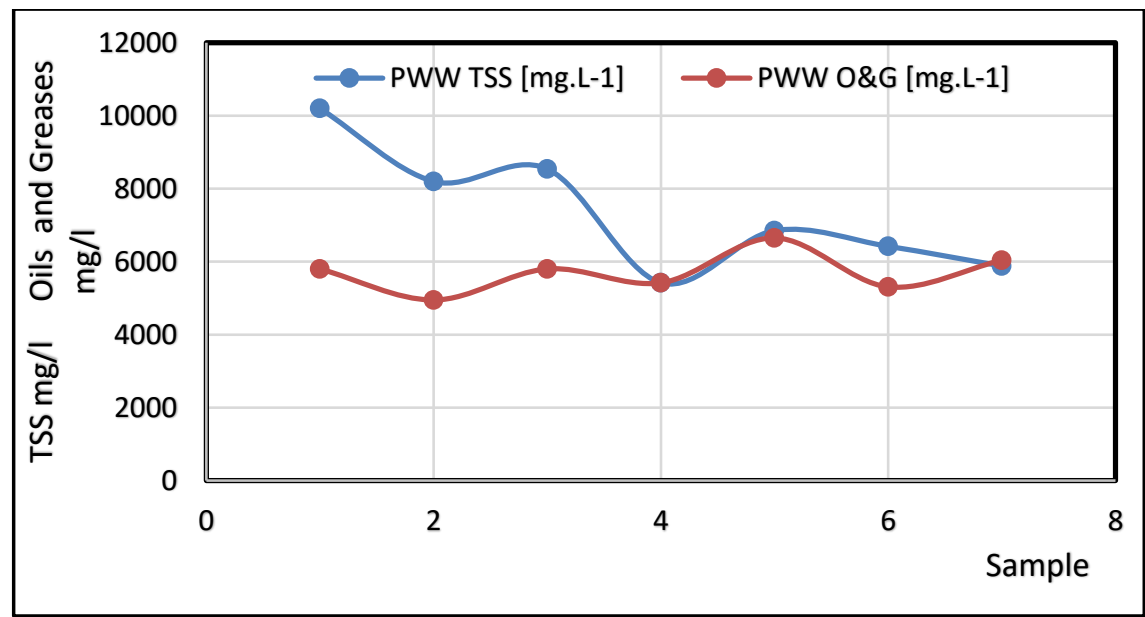

Figure 3. The relationship between TSS and fat concentration.

The variation of the pollutant loads of fats and oils and suspended matter $\mathrm{kg} / \mathrm{d}$ for six weeks is illustrated in Figures 4 and 5, respectively.

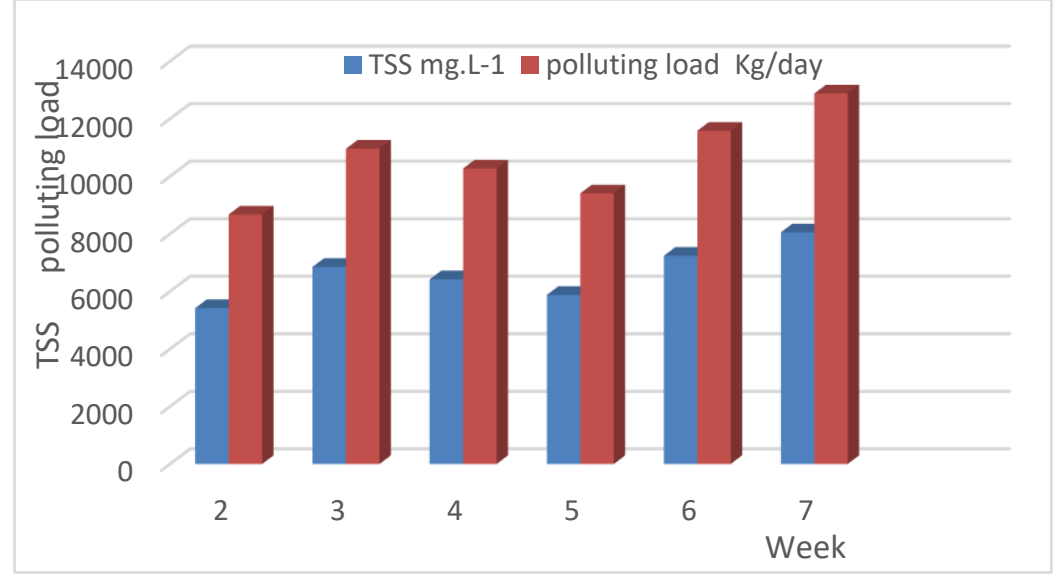

Figure 4. Variation of the concentration and pollutant load of TSS.

The pollutant load in TSS varies around $8000 \mathrm{~kg} / \mathrm{j}$ as a minimum value and 12000 $\mathrm{kg} / \mathrm{j}$ as a maximum value related to oils and greases in process wastewater. 


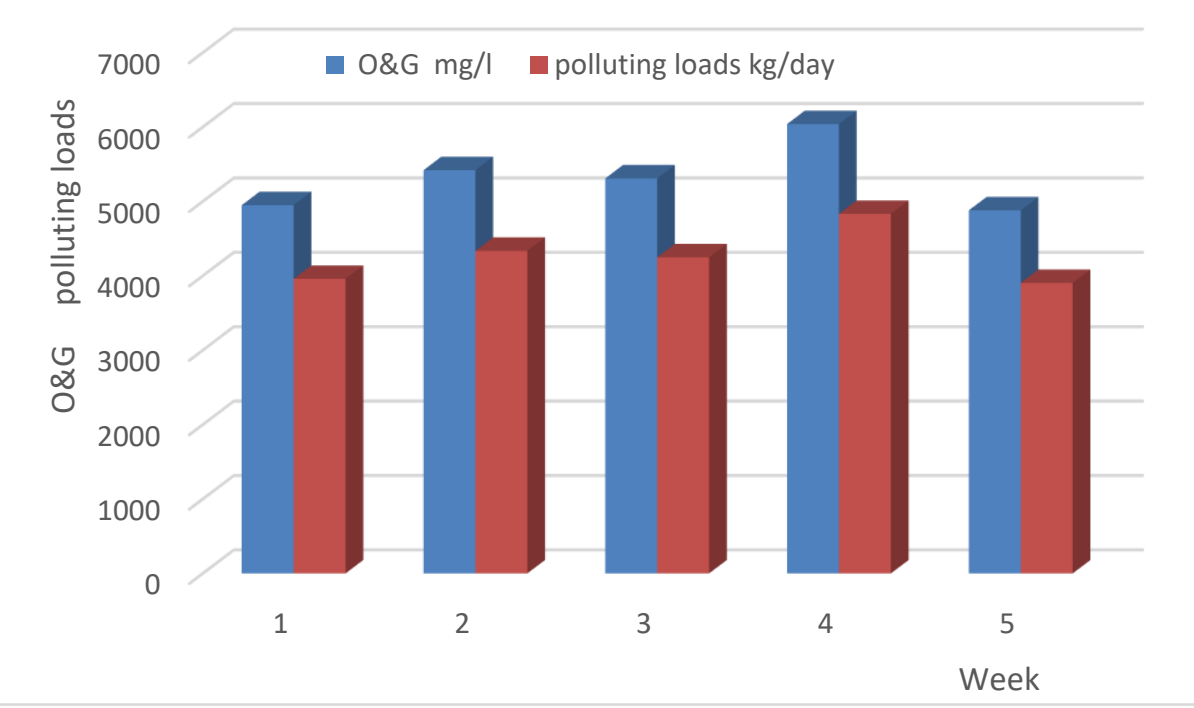

Figure 5. Variation of the pollutant load over time.

The pollutant load of TSS and oils and greases discharged is strongly influenced by the production process that operates $24 / 24$ and produces different types of items over time. The turbidity is proportional to the concentration of TSS. These results show that the reduction in pollution in terms of COD and BOD5 is correlated with eliminating fats and oils on the one hand. On the other hand, turbidity has a good correlation with the TSS, as reported by CisternaOsorio and Arancibia-Avila (2019) [22] and Kastali et al. (2020) [23].

\subsubsection{Effect of $\mathrm{pH}$ on the reduction of turbidity and sludge production.}

This work aimed to show the effect of $\mathrm{pH}$ and $\mathrm{FeCl}_{3} 30 \%$ (SIWW) on eliminating turbidity and the production of sludge for industrial refinery rejection. The $\mathrm{pH}$ effect was achieved by adopting the jar test conditions described above and adjusting the $\mathrm{pH}$ with sodium hydroxide or $\mathrm{H}_{2} \mathrm{SO}_{4}$. The results obtained are illustrated in Table 2.

Table 2. Effect of $\mathrm{pH}$ on the reduction of turbidity and sludge production. Initial turbidity $=447 \mathrm{NTU}, \mathrm{pH}=2,8$, decantation time $=2$ hours.

\begin{tabular}{c|c|c|c}
$\mathbf{p H}$ & $\begin{array}{c}\text { Turbidity } \\
(\mathbf{N T U})\end{array}$ & Efficiency $(\%)$ & Sludges $(\mathbf{m l} / \mathbf{l})$ \\
\hline 2.8 & 447.3 & - & - \\
\hline 4.5 & 8.31 & 98,1 & - \\
\hline 5 & 7.1 & 98,5 & - \\
\hline 5.5 & 2.53 & 99,4 & - \\
\hline 6 & 2.26 & 99,5 & 65 \\
\hline 7 & 1.09 & 99,8 & 62 \\
\hline 8 & 5.31 & 98,8 & 80 \\
\hline 9.2 & 6.74 & 98,5 & 76 \\
\hline 10 & 7.31 & 98,4 & - \\
\hline 11 & 3.52 & 99.2 & - \\
\hline 12 & 2.72 & 99,4 & 86
\end{tabular}

These results show that the $\mathrm{pH}$ strongly influences the reduction of pollution, in particular, turbidity. The volume of sludge produced varies according to the pollutant load present in the effluent to be treated.

3.1.4. Effect of $\mathrm{pH}$ and sedimentation time on the de reduction of sludge production.

Furthermore, the production of sludge over time was carried out for different $\mathrm{pHs}$ (Figure 6). 


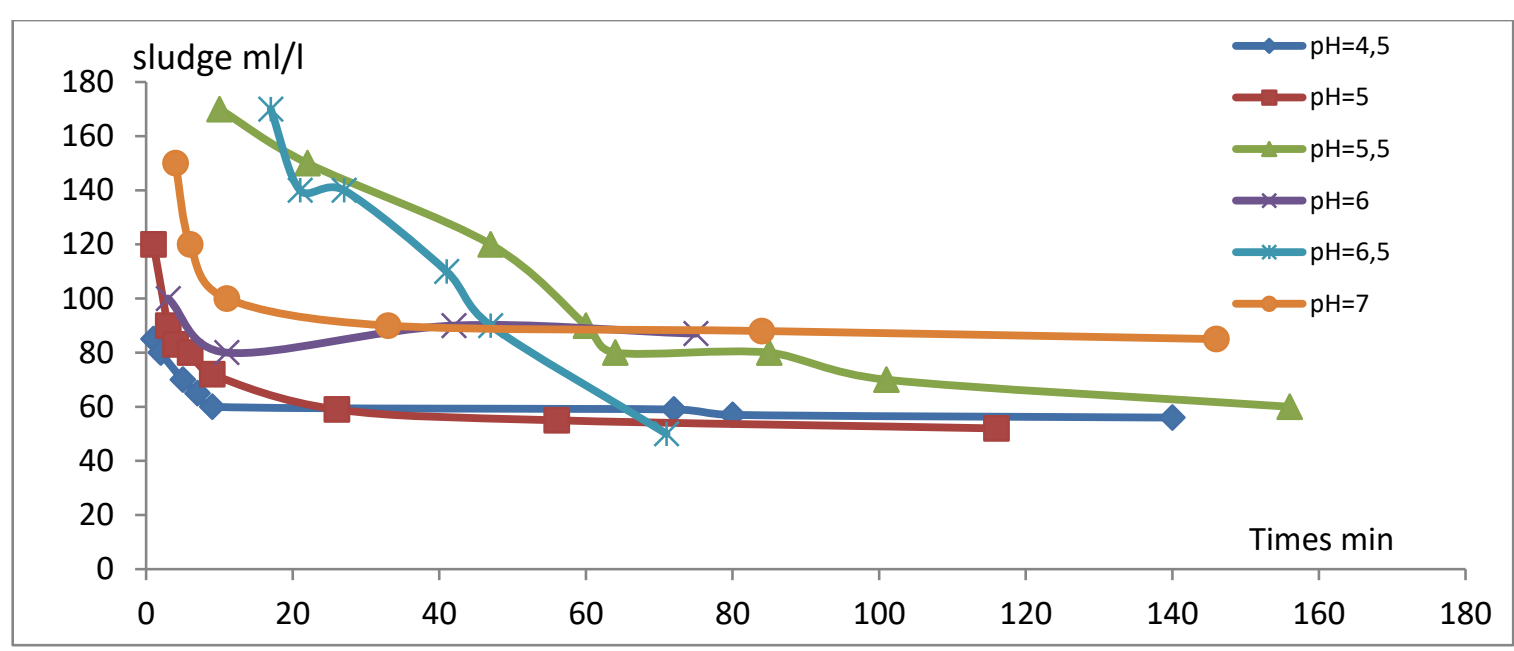

Figure 6. Effect of $\mathrm{pH}$ on the de reduction of sludge production.

These results have shown that the volume of sludge produced varies over time and with

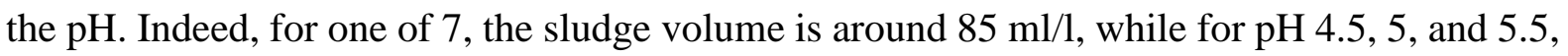
the volume of sludge varies around $60 \mathrm{ml} / \mathrm{l} /$.

\subsubsection{Effect of $\mathrm{FeCl} 330 \%$ (SIWW) on the reduction of turbidity and sludge production.}

The reduction of turbidity by $\mathrm{FeCl}_{3} 30 \%$ (SIWW) was carried out using three effluents from process water: high load, medium load, and low load. Under optimal conditions, the coagulation-flocculation process was able to reduce the turbidity.

The tests were performed based on the optimal concentrations obtained during the flocculation coagulation tests.

3.1.6. Effect of $\mathrm{FeCl}_{3} 30 \%$ (SIWW) on the reduction of turbidity by coagulation-flocculation followed by flotation: the case of heavily loaded wastewater.

Coagulation-flocculation flotation by $30 \% \mathrm{FeCl}_{3}$ was carried out to determine the optimal treatment conditions for process wastewater effluents. Coagulation is the process by which the particles become destabilized and agglutinate to settle or float depending on whether the wastewater is rich or poor in the floating matter. This technique is an essential element of water treatment operations loaded with polluting materials. The evaluation of the coagulationflocculation step's optimal conditions depends on several parameters such as the polluting load of the wastewater, the concentration of coagulants and flocculants, the $\mathrm{pH}$, the agitation. Optimal coagulant doses are essential for the proper formation of flakes that float or which settle, depending on the case of wastewater. It is necessary to maintain proper control of these chemicals in a process line. Figure 6 shows the evolution of turbidity (in the case of a high load) during coagulation by flocculation with $30 \% \mathrm{FeCl}_{3}$ (SIWW) followed by flotation at different concentrations for a settling time of $30 \mathrm{~min}$ and 24 hours.

\subsubsection{Sludge production: the case of heavily charged wastewater.}

Sludge production is the main problem of wastewater treatment in developing countries. In this study, we followed the sludge production in $\mathrm{ml} / \mathrm{l}$ obtained during the discharges' coagulation-flocculation loaded with pollutants rich in fats. The results obtained for the different $\mathrm{FeCl} 3$ 30\% concentrations used for the study by following the quantity of sludge produced for different concentrations of the coagulant are illustrated in Figure 8. 


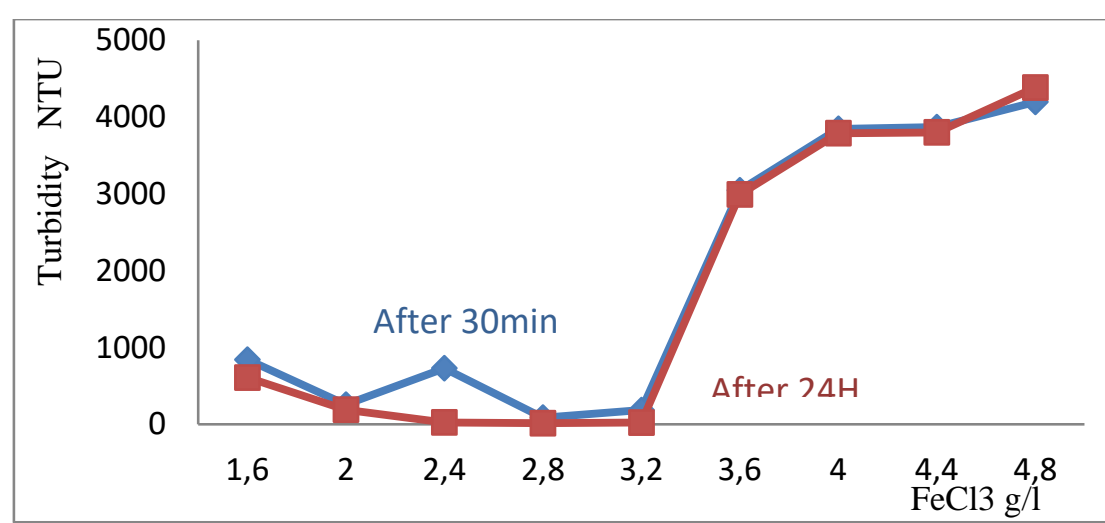

Figure 7. Effect of flotation time and $30 \% \mathrm{FeCl}_{3}$ on turbidity reduction. $\mathrm{pH}=7.2$, initial turbidity $=2538 \mathrm{NTU}$.

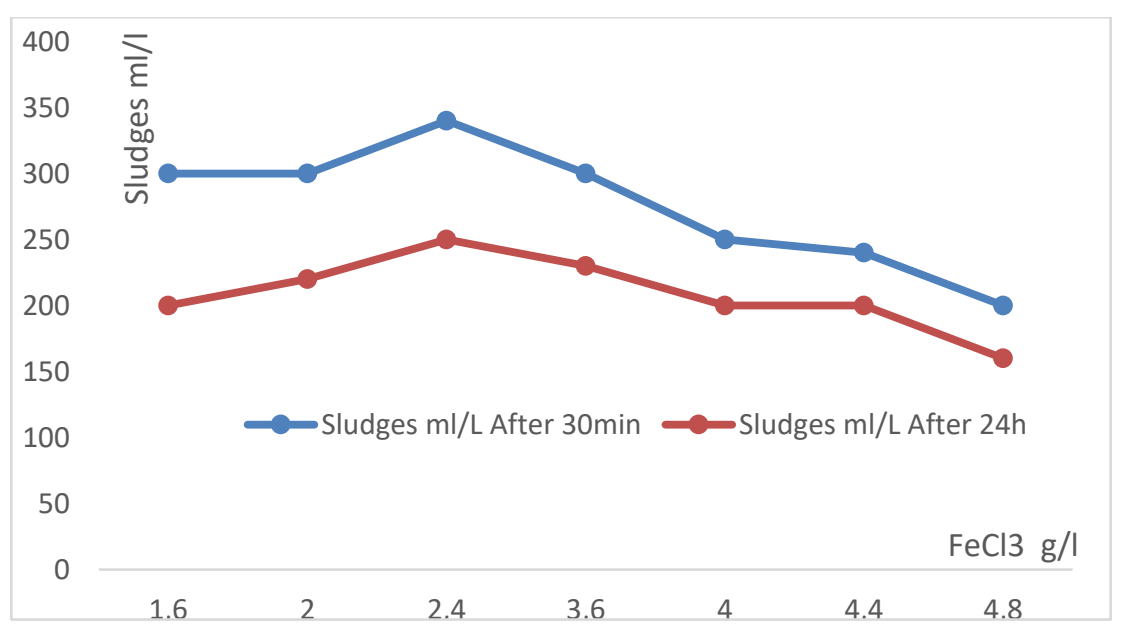

Figure 8. Effect of flotation time and $30 \% \mathrm{FeCl}_{3}$ on the production of sludge. Optimal concentration $=2.4 \mathrm{~g} / \mathrm{l}$, $\mathrm{pH}=7.2$, initial turbidity $=2538$ NTU.

3.1.8. Effect of $\mathrm{FeCl}_{3} 30 \%$ (SIWW) on the reduction of turbidity for a medium polluting load.

Recovery is a function of the pollutant load discharged from high to medium or low load. Figure 9 shows the variation of turbidity as a function of $\mathrm{FeCl}_{3} 30 \%$ for a low pollutant load.

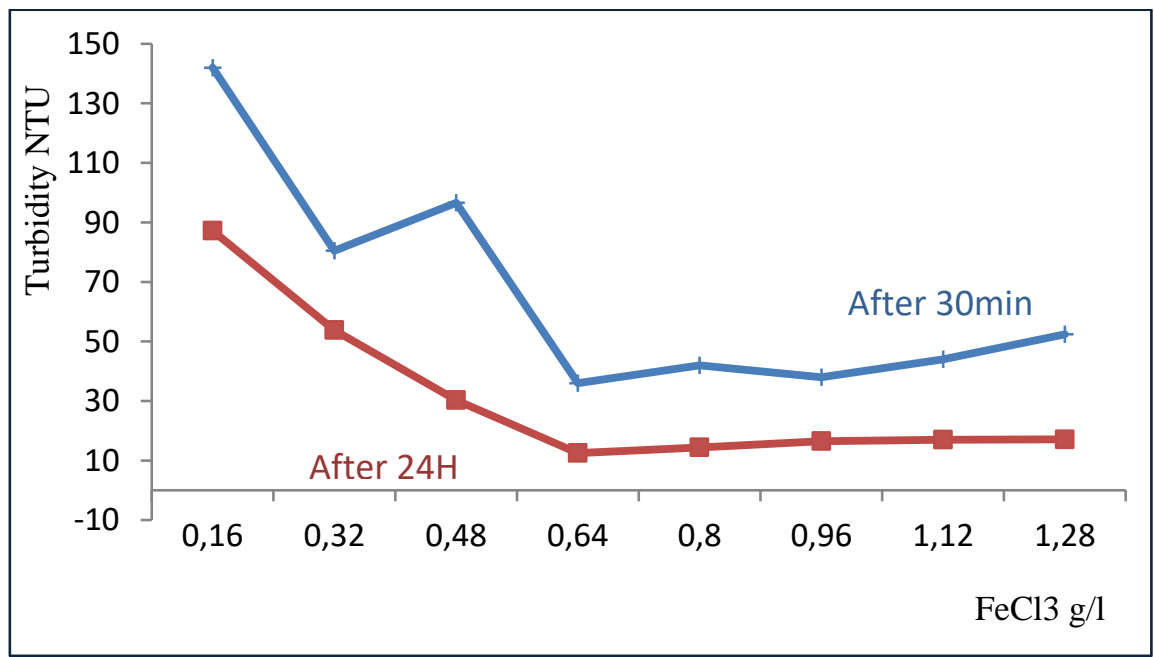

Figure 9. Reduction of turbidity. $\mathrm{pH}=7.4$, initial turbidity $=175$ NTU.

Figure 9 illustrates the effect of a medium charged effluent on the optimal concentration of $\mathrm{FeCl}_{3} 30 \%$. The monitoring of the reduction in turbidity was studied for a settling time of 30 min and 24 hours. For a settling time of 24 hours, the results showed that the turbidity went from $35 \mathrm{NTU}$ to $10 \mathrm{NTU}$ for an optimal concentration of $0.64 \mathrm{~g} / 1$ (Figure 9). 
3.1.9. Effect of $\mathrm{FeCl}_{3} 30 \%$ (SIWW) on turbidity reduction for low pollutant load.

Figure 10 illustrates the turbidity variation as a function of $30 \%$ of $\mathrm{FeCl}_{3}$ for slightly loaded process water for a sludge production time of $30 \mathrm{~min}$ and 2 hours.

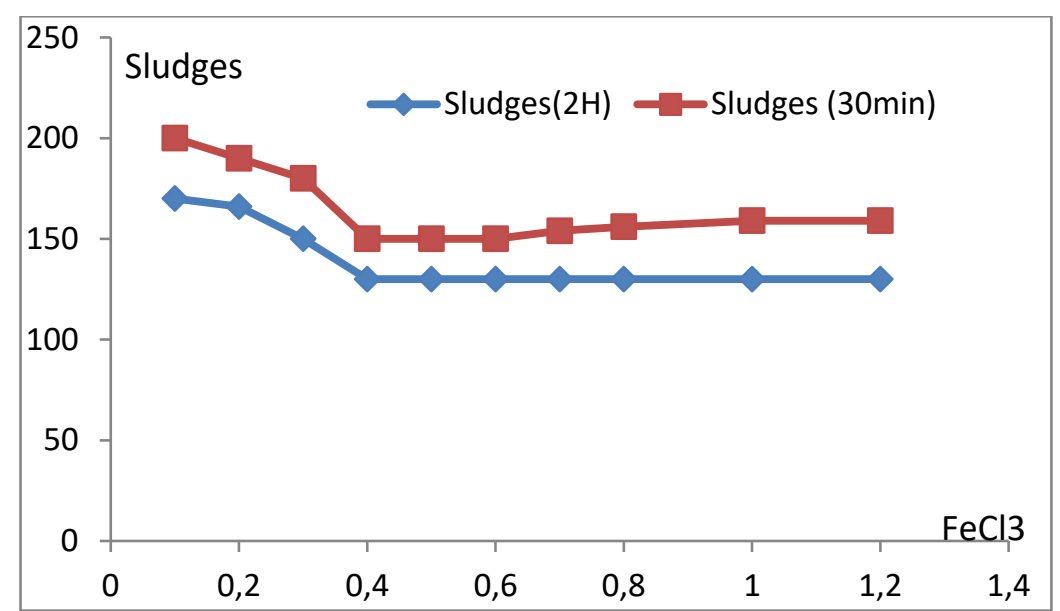

Figure 10. Effect of $\mathrm{FeCl}_{3} 30 \%$ and flotation time on sludge production: the case of low turbidity.

Little difference was observed for the two settling times $t$ of sludge production. The results obtained showed that the elimination of turbidity is maximum for an optimum concentration of $0.4 \mathrm{~g} / \mathrm{l}$ of $\mathrm{FeCl}_{3}$, which has made it possible to achieve a yield of approximately 98\% (Figure 9).

3.1.10. Comparative study of reducing pollution by $\mathrm{FeCl}_{3} 40 \%$ and $\mathrm{FeCl}_{3} 30 \%$ (SIWW).

The comparative study of eliminating turbidity by $\mathrm{FeCl}_{3} 40 \%$ and $\mathrm{FeCl}_{3} 30 \%$ is illustrated in Figure 11 (low load).

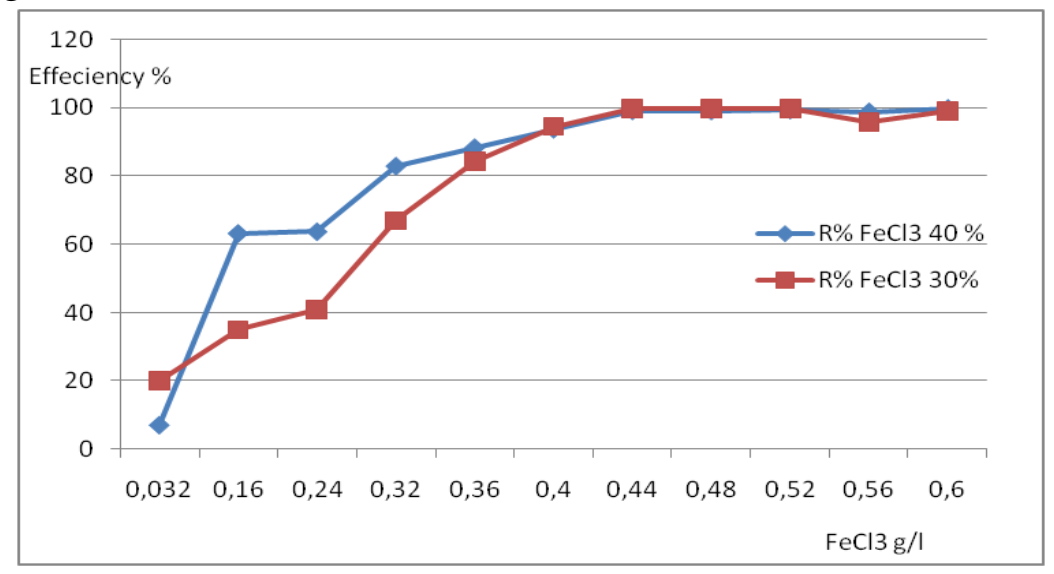

Figure 11. Comparative study of turbidity reduction with $\mathrm{FeCl}_{3} 30 \%$ (SIWW) and $\mathrm{FeCl}_{3} 40 \%$ (commercial coagulant).

The comparative study of the elimination of turbidity by $\mathrm{FeCl}_{3} 40 \%$ and the industrial discharge rich in $\mathrm{FeCl}_{3} 30 \%$ for a low load (Figure 10) made it possible to show that the industrial effluent rich in $\mathrm{FeCl}_{3} 30 \%$ could be recovered as a coagulant for reducing pollution of process wastewater.

\subsection{Discussion.}

The main pollutants in wastewater from the vegetable oil refinery industry were organic compounds and suspended solids and fats. The results obtained (Table 1) show that process 
water is heavily loaded with pollutants. These high values can disrupt the functioning of the sewerage network and even the treatment plant. An upstream action plan helps minimize the impact on corrosion of the sewerage network. The composition of process wastewater in the same varies considerably over time. In fact, in a refinery, the fluctuations observed in wastewater are attributed to the operating conditions and process and the different types of oils processed [8]. The characteristics of wastewater are influenced not only by processed products and raw materials but also by the water used in manufacturing processes during and after production [20]. These factors strongly influence the observed variation in the values of all the physicochemical parameters (COD, BOD5, TSS, oils, and greases, etc.). Studying the biodegradability of an industrial effluent rich in oil and fats [22] was shown the relationship between the elimination of fat and sunflower oil and the chemical oxygen demand.

The COD concentration in the process water has a minimum value of 43.5 and $53.6 \mathrm{~g} / \mathrm{l}$ as the maximum value. Besides, the BOD5 concentration admits as a maximum value of $25 \mathrm{~g} / \mathrm{l}$ and $2.1 \mathrm{~g} / \mathrm{l}$ as a minimum value, while the TSS concentration has a maximum value of 572 $\mathrm{mg} / \mathrm{l}$. This is strongly related to the presence of fats and oils in the wastewater studied. Similar values have been reported by Dkhissi et al. (2020) [24], while lower values were reported by Anyanwu et al. (2019) [25] and by Pešević et al. (2019) [26]. Wastewater with a basic pH is rich in toxic pollutants for the environment, particularly phenol, which has a concentration varying between $58.3 \mathrm{mg} / \mathrm{l}$ as an average value and $33.4 \mathrm{mg} / 1$ as a minimum value with an average of $46.3 \mathrm{mg} / \mathrm{l}$. Also, the detergents have a definite impact on the proper functioning of the company's wastewater treatment plant since the production of foams in the biological basin disrupts the development of biomass, which can lead to poor decantation at the level of the clarifier of the satisfaction of Lesieur society as indicated by Dkhissi et al. (2020) [24]. Serajuddin et al. (2019) [21] obtained the results concerning the treatment of urban wastewater, showing that TSS and turbidity have a strong correlation. The authors used turbidity to estimate total TSS over time. Several researchers attribute this fluctuation in the characteristics of the wastewater from vegetable oils and biodegradability to several elements, particularly the production process, the types of oils produced by the industrial unit [24], and the operating conditions and processes from the factory [27]. The studied discharges' physicochemical characteristics show fluctuations over time, which is due to the manufacturing processes of the various products, oils, detergents, bleach, and cosmetic products [24]. The COD/BOD5 ratio varies between 3.4 and 6.7, thus showing that the polluting matter of wastewater is not easily biodegradable and varies over time, which may be linked to the presence of fats and oils in strong concentrations [24]. The COD/BOD5 ratio was used to assess wastewater's biodegradability from a vegetable oil refinery after oxidation by $\mathrm{H}_{2} \mathrm{O}_{2}$ [28].

We note that the process wastewater that the Lesieur treatment plant treats has physicochemical characteristics that differ from one partner to another. These fluctuations attributed to the operating conditions and processes and the different types of oils processed [5, 8]. The characteristics of wastewater are influenced not only by processed products and raw materials but also by the water used in washing procedures during and after production [5, 7], [20]. Its characteristics depend largely on the type of oil processed, resulting in both high inorganic as well as organic pollutants. Many methods are available to treat the organic content.

A great deal of literature is available on this aspect, such as reverse osmosis [21]. Biodegradability can be estimated based on the ratio between BOD5 and COD. In this case, BOD5/COD varies around 0.3 and 0,15 for the average values of COD and BOD5, which indicates that most of the organic compounds in wastewater are not readily biodegradable. If 
the BOD / COD ratio is between 0.3 and 0.6 , it is compulsory to biologically treat an effluent's seeding. If $\mathrm{BOD} / \mathrm{COD}<0.3$, organic pollutants in the wastewater are not biodegradable, and biological treatment cannot be used alone.

These results show that the pollutant loads of fats and oils and TSS vary over time. The concentration of fats and oils varies between 5000 and $6000 \mathrm{mg} / \mathrm{l}(4000$ and $4800 \mathrm{~kg} / \mathrm{day})$ pollutant load, while TSS varies between 5500 and $8000 \mathrm{mg} / \mathrm{l}$ (9400 and $13600 \mathrm{~kg} /$ day). This strongly influences the turbidity of the wastewater, which in some cases exceeds 4000 NTU. This fluctuation of the pollutant loads strongly influences the optimal concentration of coagulants and flocculants during the treatment of the wastewater by the company's station, which treats the wastewater according to the diagram in Figure 2. The treatment process comprises a coagulation-flocculation by $\mathrm{FeCl}_{2}$ and a cationic flocculant followed by an SBR (sequential batch reactor) type biological treatment. The results obtained by Chatoui et al. 2016 [8] showed that coagulation-flocculation is strongly influenced by the pollutant load, which changes over time. It should be noted that the wastewater received by the station is made up of a mixture of three types of discharge (process wastewater, acidic wastewater, and soap water). The physicochemical characteristics of the three types of water change over time, which could have a considerable effect on the optimal physicochemical and biological treatment conditions at the treatment plant level (Figure 2).

The composition of process wastewater in the same varies considerably over time. In fact, in a refinery, the fluctuations observed in wastewater are attributed to the operating conditions and process, and the different types of oils processed [8]. The characteristics of wastewater are influenced not only by processed products and raw materials but also by the water used in manufacturing processes during and after production [20]. These factors strongly influence the observed variation in the values of all the physicochemical parameters (COD, BOD5, TSS, oils, and greases, etc.). Similar values have been reported by Dkhissi et al. (2018) [5], while lower values have been reported by Anyanwu et al. (2019) [25] and Pešević et al. (2019) [26]. Characterization of wastewaters is important as it is very useful for the control and development of treatment processes [29-31].

The results showed that the turbidity at $\mathrm{pH} 7$ increased from 447 to 1.09 with a $99 \%$ reduction yield. These results are comparable with those obtained by Anouzla et al. (2017) [32], which used $30 \% \mathrm{FeCl} 3$ to decontaminate agro-food wastewater. Indeed, the basic $\mathrm{pH}$ could have an exciting impact on reducing pollution, particularly turbidity, while producing compacted sludge. These results agree with those obtained by et Dkhissi et al. (2018) [5], who used $\mathrm{FeCl} 3$ to reduce pollution of industrial wastewater. The results obtained by the latter showed that a considerable reduction in COD and turbidity were obtained. The same authors have shown that the metallic elements are strongly eliminated at basic $\mathrm{pH}$. in the form of hydroxides. In conclusion, sedimentation is strongly influenced by $\mathrm{pH}$.

The results obtained show no significant difference for a settling time of $30 \mathrm{~min}$ and 24 hours for the different concentrations used for the study. The optimum concentration varies around $2.4 \mathrm{~g} / 1$ of $30 \% \mathrm{FeCl}_{3}\left(\mathrm{SIWW}\right.$ ) (Figure 6). However, from $3.2 \mathrm{~g} / 1$ of $\mathrm{FeCl}_{3}$, the turbidity increases, which is linked to the excess $\mathrm{FeCl}_{3}$ used, which justifies poor coagulationflocculation followed by flotation. Under optimal conditions, the coagulation-flocculation process reduced turbidity 820 NTU from to 15 NTU (98\% efficiency) with $\mathrm{pH} 7.2$. The 30 min and 24 hour settling times did not show a significant difference in removing turbidity. The elimination efficiency obtained varies around $98 \%$ for a concentration variant of between 2.8 and $3.2 \mathrm{~g} / 1$ ( 2.8 and $3.2 \mathrm{~kg} / \mathrm{m} 3)$ with a cost of 1.1 dollars $/ \mathrm{m}^{3}$. It has been shown by Bakraouy 
et al. (2016) [33] that the process of coagulation-flocculation and sedimentation could be used to reduce suspended solids and turbidity in wastewater. In addition, Majdy et al. (2015) [34] have shown that $\mathrm{FeCl}_{3}$ allows a very significant reduction in turbidity during the treatment of urban wastewater in the city of Salé. Moreover, it has been shown that industrial wastewater (SIWW) loaded with $\mathrm{FeCl}_{3}$ has led to a good reduction in pollution of industrial wastewater loaded with dyes [35-36].

The results obtained showed the elimination of $99 \%$ of the coloring and $94 \%$ of the COD. This shows that the effluents discharged by the company Maghreb Steel can be recovered to reduce pollution due to industrial discharges, in particular agro-food discharges, at the lowest cost. Optimal coagulant dosages are essential for the proper formation of flakes that can settle or float. Maintaining proper control of these chemicals in a wastewater treatment plant is necessary

The production of sludge was monitored for two settling times (30 min and 24 hours). The results have shown that the maximum volume obtained for the optimal concentration of $2.4 \mathrm{~g} / \mathrm{l}$ varies around $350 \mathrm{ml} / \mathrm{l}$ for a settling time of $30 \mathrm{~min}$, while it is $250 \mathrm{ml} / \mathrm{l}$ for a settling time of 24 hours. This shows that we are witnessing a sludge compression for a settling time of 24 hours. In conclusion, the settling time and the concentration of $\mathrm{FeCl}_{3} 30 \%$ strongly influence the sludge volume produced during treatment. This could strongly influence the dryness of the sludge rich in oils and fats and can be used as a source of energy.

Indeed, Moroccan regulations do not authorize the discharge of sludge into the natural media before treatment. Demirbas et al. (2017) [36] have shown that the sludge produced by treatment plants must be treated since it is rich in several types of urban and industrial contaminants. Filibeli et al. (2018) [37] have shown that the sludge from sewage treatment plants is a complex environment containing lipids, detergents, etc. Therefore treatment is necessary before discharge into the environment. Besides, Collivignarelli et al. (2019) [38] have shown that technologies for minimizing the production of sewage sludge are based on three different strategies:

-adopt a process in the water pipe that reduces the production of sludge;

-reduce the maximum possible dryness;

-reduce the fraction of volatile solids (stabilization).

Furthermore, Wei et al. (2016) [39] have shown that the main mechanisms for removing organic matter from wastewater using a coagulant have generally been attributed to adsorption, trapping, complexing, neutralization of the charge which could accumulate all organic and inorganic pollutants in the sludge. The main coagulation mechanism for organic matter (negatively charged) removal using a positively charged coagulant is charge neutralization [7].

In general, a charge neutralization takes place when the coagulants and the adsorption site are of opposite charge. The flocculation results in the reduced surface charge of the particles and hence a decreased electrical repulsion force between colloidal particles (mainly phenolic compounds), which allows the formation of Van Der Waals force of attraction to encourage the initial aggregation of colloidal and fine suspended solids and the reduction of turbidity

Many techniques can be applied to eliminate them [37]. In the present work, a study on reducing turbidity while monitoring the production of sludge was carried out to optimize the effectiveness of the treatment and reduce the quantity of sludge [17]. Bakraouy et al. (2016) [33] showed that $\mathrm{FeCl}_{3}$ produced compacted sludge that was easy to dehydrate. 
Besides, the reduction of turbidity by $30 \% \mathrm{FeCl}_{3}$ has been studied for two types of pollutant load (medium load and high load) (Figure 8). For the effluent at medium load, the optimum concentration of $0.64 \mathrm{~g} / 1$ of $30 \% \mathrm{FeCl}_{3}$ allowed a very significant turbidity reduction. The monitoring of the reduction in turbidity was studied for a stabilization time of $30 \mathrm{~min}$ and 24 hours.

The study of the effect of $\mathrm{FeCl}_{3} 30 \%$ and the flotation time on sludge production has shown very interesting results for the reduction of turbidity (Figure 9). Little difference was observed for both settling times and sludge production. Therefore, it is necessary to subject the water to natural flotation before the coagulation-flocculation to reduce the cost of the treatment. The flocculation coagulation results obtained on raw process water compared to those obtained with floated wastewater showed a reduction of $0.3 \mathrm{~g} / 1$ of $30 \% \mathrm{FeCl}_{3}$ coagulant. Consequently, the optimum concentration for float process water varies around $0.4 \mathrm{~g} / \mathrm{l} \mathrm{FeCl} 3$ while that obtained for raw wastewater varies around $0.7 \mathrm{~g} / \mathrm{l}$. In conclusion, for wastewater rich in floating matter, it is very interesting to subject the water to natural flotation before moving on to coagulation-flocculation.

The results obtained showed that for concentrations of $\mathrm{FeCl}_{3} 40 \%$ less than $0.4 \mathrm{~g} / \mathrm{l}$ the yield is better compared to the results obtained with $\mathrm{FeCl}_{3} 30 \%$ (Figure 10). However, from a concentration of $0.44 \mathrm{~g} / \mathrm{l}$, the two coagulants' yield remains the same (approximately $98 \%$ elimination). These results show that the recovery of industrial discharge rich in $\mathrm{FeCl}_{3} 30 \%$ makes it possible to reduce pollution considerably. He points out that the quality of process wastewater varies throughout the day and from day-to-day. The results obtained by Anouzla $e t$ al. (2009) [40] by using the same coagulant $\left(\mathrm{FeCl}_{3}\right.$ 30\%) for the treatment of textile rejects made it possible to considerably reduce COD and the color of wastewater laden with dyes $94 \%$ and 99\%, respectively. The coagulant $\mathrm{FeCl}_{3} 30 \%$ (SIWW) had the best performance in removing turbidity of vegetable oil industry wastewater, achieving greater efficiencies $99 \%$ for low and high pollution load with an optimal dose of $1.48 \mathrm{~g} / \mathrm{l}$. Furthermore, Anouzla 2019 [41] showed that $\mathrm{FeCl}_{3}$ could reduce pollution from discharges of stabilized leachate.

Optimal elimination of turbidity was obtained with a dose of $440 \mathrm{mg} / \mathrm{l}$ for ferric chloride $40 \%$ and ferric chloride $30 \%$. Coagulation with $\mathrm{FeCl}_{3}(30 \%)$ as an industrial release has shown excellent turbidity elimination [42]. The initial value of turbidity ranges from 652 NTU to around 12

In this work, we studied the reduction of the turbidity of the pollution of refinery wastewater and sludge production during treatment by an industrial rejection of iron and steel industry rich in $\mathrm{FeCl}_{3} 30 \%$. This makes it possible to prevent the valorization of the discharge rich in $\mathrm{FeCl}_{3}$ while monitoring the sludges' production during the treatment by flocculation coagulation so that the use of the discharge can be prevented for the de-pollution of agro-food discharges, in particular the discharges of wastewater produced Lesieur Ain Harrouda Casablanca. Achak et al. (2019) [7], showed that the treatment of wastewater with $\mathrm{FeCl}_{3}$ gave a removal in $\%$ of high turbidity of approximately $95 \%$ at the dose of $40 \mathrm{mg} / \mathrm{l}$ with a percentage of elimination of COD of approximately $90 \%$ for a $\mathrm{pH}-4$.

The comparative study of the elimination of turbidity by $\mathrm{FeCl}_{3} 40 \%$ and the industrial discharge rich in $\mathrm{FeCl}_{3} 30 \%$ for a low load (Figure 10) made it possible to show that the industrial effluent rich in $\mathrm{FeCl}_{3} 30 \%$ could be recovered as a coagulant for reducing pollution of process wastewater. 


\section{Conclusions}

The disposal of industrial steel wastewater ( $\mathrm{SIWW}$ ) rich by $\mathrm{FeCl}_{3} 30 \%$ production is a serious concern for WWTPs due to environmental and socio-economic factors. Therefore, selecting an effective and sustainable way for SIWW management is a challenge for wastewater treatment authorities. In the context of the circular economy, SIWW is no longer regarded as polluted but rather as a valuable resource for treating wastewater.

Coagulation flocculation by $\mathrm{FeCl}_{3} 30 \%$ (SIWW) has shown that the latter makes it possible to achieve a very interesting reduction in pollution, in particular turbidity. The sludge production in $\mathrm{ml} / \mathrm{l}$ is a function of the wastewater studied quality and the optimal concentration of $\mathrm{FeCl}_{3}$ used.

In the present work, an evaluation of a coagulation adjuvant - flocculation commonly used ferric chloride contained in an industrial effluent rejected by the steel company was carried out to determine the optimal conditions for treatment of process wastewater effluents for three types of polluting loads (high load, medium load, and low load). The $\mathrm{FeCl}_{3} 30 \%$ considerably reduces the turbidity compared to the commercial $\mathrm{FeCl} 340 \%$ results. Flocculation coagulation tests were carried out to assess the dosages and conditions necessary to reach the optimal conditions for wastewater treatment while respecting Morocco's discharge standards.

\section{Funding}

This research received no external funding.

\section{Acknowledgments}

This research has no acknowledgments.

\section{Conflicts of Interest}

The authors declare no conflict of interest.

\section{References}

1. Hung, Y.-T.; Kaya, D. Treatment of Vegetable Oil Refining Wastes. "Evolutionary Progress in Science, Technology, Engineering, Arts, and Mathematics (STEAM)" 2020, 1-80.

2. Meyer, A.M.; Klein, C.; Fünfrocken, E.; Kautenburger, R.; Beck, H.P. Real-time monitoring of water quality to identify pollution pathways in small and middle scale rivers. Sci. Total Environ. 2019, 651, 2323-2333, https://doi.org/10.1016/j.scitotenv.2018.10.069.

3. El-Naas, M.H.; Al-Zuhair, S.; Alhaija, M.A. Removal of phenol from petroleum refinery wastewater through adsorption on date-pit activated carbon. Chem. Eng. J. 2010, 162, 997-1005, https://doi.org/10.1016/j.cej.2010.07.007.

4. Iloms, E.; Ololade, O.O.; Ogola, H.J.O.; Selvarajan, R. Investigating Industrial Effluent Impact on Municipal Wastewater Treatment Plant in Vaal, South Africa. Int. J. Env. Res. Public Health 2020, 17, 1096, https://doi.org/10.3390/ijerph17031096.

5. Dkhissi, O.; El Hakmaoui, A.; Souabi, S.; Chatoui, M.; Jada, A.; Akssira, M. Treatment of vegetable oil refinery wastewater by coagulation-flocculation process using the cactus as a bio-flocculant. J Mater Environ Sci 2018, 9, 18-25, https://doi.org/10.26872/jmes.2018.9.1.3.

6. Kweinor Tetteh, E.; Rathilal, S.; Robinson, K. Treatment of industrial mineral oil wastewater-effects of coagulant type and dosage. Water practice and technology 2017, 12, 139-145, https://doi.org/10.2166/wpt.2017.021. 
7. Achak, M.; Elayadi, F.; Boumya, W. Chemical coagulation/flocculation processes for removal of phenolic compounds from olive mill wastewater: a comprehensive review. American J. Appl. Sci 2019, 16, 59-91, https://doi.org/10.3844/ajassp.2019.59.91.

8. Chatoui, M.; Lahsaini, S.; Aguelmous, A. Removal of oil and grease from vegetable oil refinery wastewaters by coagulation-flocculation process. Moroccan Journal of Chemistry 2017; 5, https://doi.org/10.48317/IMIST.PRSM/morjchem-v5i4.7509.

9. Kulkarni, S.J. Role of Adsorption in Petroleum Industries and Refineries. International Journal of Petroleum and Petrochemical Engineering 2016, 2, 1-4, https://doi.org/10.20431/2454-7980.0201004.

10. Shahriari, T.; Karbassi, A.R.; Reyhani, M. Treatment of oil refinery wastewater by electrocoagulationflocculation (Case Study: Shazand Oil Refinery of Arak). Int. J. Environ. Sci. Technol. (Tehran) 2019, 16, 4159-4166, https://doi.org/10.1007/s13762-018-1810-z.

11. Robinson, T. Removal of toxic metals during biological treatment of landfill leachates. Waste Manage. 2017, 63, 299-309, https://doi.org/10.1016/j.wasman.2016.12.032.

12. Fatah, M.M.A.A.; Al Bazedi, G.A. Chemically Enhanced Primary. European Journal of Engineering Research and Science 2019, 4, 115-123, https://doi.org/10.24018/ejers.2019.4.4.1252.

13. Tian, Y.P.; Wang, B. Experimental Study of Optimal Coagulation Effect on Three Kinds of Direct Sun-Proof Dyes by FeCl3. Advanced Materials Research 2013, 690-693, 1504-1507, https://doi.org/10.4028/www.scientific.net/AMR.690-693.1504.

14. Ghernaout, D. Virus removal by electrocoagulation and electrooxidation: New findings and future trends. Journal of Environmental Science and Allied Research 2019, 2019, 85-90, https://doi.org/10.29199/26377063/ESAR-202024.

15. Achak, M.; Boumya, W.; Ouazzani, N.; Mandi, L. Preliminary evaluation of constructed wetlands for nutrients removal from olive mill wastewater (OMW) after passing through a sand filter. Ecol. Eng. 2019, 136, 141-151, https://doi.org/10.1016/j.ecoleng.2019.06.007.

16. Bhanvase, B.A.; Ugwekar, R.P.; Mankar, R.B. Novel water treatment and separation methods: Simulation of chemical processes; CRC Press: 2017.

17. Wang, S.; Ma, C.; Zhu, Y.; Yang, Y.; Du, G.; Li, J. Deep dewatering process of sludge by chemical conditioning and its potential influence on wastewater treatment plants. Environmental Science and Pollution Research 2019, 26, 33838-33846, https://doi.org/10.1007/s11356-018-2351-1.

18. Triques, C.C.; Fagundes-Klen, M.R.; Suzaki, P.Y.R.; Mateus, G.A.P.; Wernke, G.; Bergamasco, R.; Rodrigues, M.L.F. Influence evaluation of the functionalization of magnetic nanoparticles with a natural extract coagulant in the primary treatment of a dairy cleaning-in-place wastewater. Journal of Cleaner Production 2020, 243, 118634, https://doi.org/10.1016/j.jclepro.2019.118634.

19. Chawaloesphonsiya, N.; Wongwailikhit, K.; Bun, S.; Painmanakul, P. Stabilized Oily-Emulsion Separation Using Modified Induced Air Flotation (MIAF): Factor Analysis and Mathematical Modeling. Eng. J. 2019, $23,29-42$.

20. Jamali, H.A.; Moradnia, M. Optimizing functions of coagulants in treatment of wastewater from metalworking fluids: Prediction by RSM method. ehemj 2018, 5, 15-21, https://doi.org/10.15171/EHEM.2018.03.

21. Serajuddin, M.; Chowdhury, M.A.I.; Haque, M.M.; Haque, M.E. Using Turbidity to Determine Total Suspended Solids in an Urban Stream: A Case Study. International Journal of Engineering Trends and Technology (IJETT) 2019, 67, https://doi.org/10.14445/22315381/IJETT-V67I9P214.

22. Cisterna-Osorio, P.; Arancibia-Avila, P. Comparison of Biodegradation of Fats and Oils by Activated Sludge on Experimental and Real Scales. Water 2019, 11, 1286.

23. Kastali, M.; Mouhir, L.; Assou,M.; Anouzla,A.; Abrouki, Y. Diagnosis of leachate from a closed landfill , impact on the soil , and treatment by coagulation flocculation with alginate and ferric chloride. Desalination and Water Treatment 2020; 206: 307-314. https://doi.org/10.5004/dwt.2020.26303.

24. Dkhissi, O.; Chatoui, M.; El Hakmaoui, A.; Abouri, M.; Kadmi, Y.; Akssira, M.; Souabi, S. Valorization of Opuntia ficus-Indica Pads and Steel Industry FeCl3-Rich Rejection for Removing Surfactant and Phenol from Oil Refinery Wastewater Through Coagulation-Flocculation. Journal of Health and Pollution 2020, 10, https://doi.org/10.5696/2156-9614-10.28.201204.

25. Anyanwu E. D.; Dike M. C.; Onyele O. G. Quality Assessment of Vegetable Oil Effluent Discharged into a Southeastern Nigeria River. African Journal of Environment and Natural Science Research 2019, 2, 1-11. 
26. Dušica, P.; Nebojša, K.; Mirjana, M. Quality Assessment of Vegetable Oil Effluent Discharged into Sava River. Arhiv za Tehnicke Nauke/Archives for Technical Sciences 2019, 21, https://doi.org/10.7251/afts.2019.1121.085P.

27. Donald, AE.; Chizuruoke, DM.; Gladys, OO. Quality assessment of vegetable oil effluent discharged into a southeastern nigeria river. African Journal of Environment and Natural Science Research, 2019;2 (1) :1-11.

28. Dhanke, P.; Wagh, S. Treatment of vegetable oil refinery wastewater with biodegradability index $\begin{array}{llllll}\text { improvement. } \quad \text { Materials } & \text { Today: } & \text { Proceedings } & \mathbf{2 0 2 0}, & 27, & 181-187 \text {, }\end{array}$ https://doi.org/10.1016/j.matpr.2019.10.004.

29. Zinatizadeh, A.A.; Akhbari, A.; Farhadian, M.; Mansouri, Y.; Pirsaheb, M.; Amirsaie, R. Influence of Process and Operational Factors on a Sequencing Batch Reactor (SBR) Performance Treating Stimulated Dairy Wastewater. mdrsjrns 2011, 0, 111-124.

30. Sridhar, S.; Kale, A.; Khan, A.A. Reverse osmosis of edible vegetable oil industry effluent. J. Membr. Sci. 2002, 205, 83-90, https://doi.org/10.1016/S0376-7388(02)00065-0.

31. Zhong, J.; Sun, X.; Wang, C. Treatment of oily wastewater produced from refinery processes using flocculation and ceramic membrane filtration. Sep. Purif. Technol. 2003, 32, 93-98, https://doi.org/10.1016/S1383-5866(03)00067-4.

32. Anouzla, A. ; Abrouki, Y.; Souabi, S.; Safi, M.; Rhbal, H. COD Reduction of Food Wastewater using SIWW Coagulant Optimization by Response Surface Methodology. Chem Eng Process Tech, 2017; 3, 1036.

33. Bakraouy, H.; Souabi, S.; Khalid, D. Valorization of a rejection rich in FeCl3 from steel industry for the treatment of landfill leachate by coagulation. 2016, 7, 3154-3161.

34. Majdy, I.; Cherkaoui, E.; Nounah, A.; Khamar, M. The physico-chemical treatment by coagulation flocculation of wastewater discharges from the city of sale. Journal of Materials and Environmental Science 2015, 6, 834-839.

35. Anouzla, A.; Abrouki, Y.; Souabi, S.; Safi, M.; Loukili, H.; Rhbal, H.; Slimani, R. Optimisation of coagulation process with SIWW is coagulant for colour and COD removal of acid dye effluent using central composite design experiment. International Journal of Environmental Monitoring and Analysis 2014, 2, 1, https://doi.org/10.11648/j.ijema.s.2014020601.11.

36. Demirbas, A.; Edris, G.; Alalayah, W.M. Sludge production from municipal wastewater treatment in sewage treatment plant. Energy Sources, Part A: Recovery, Utilization, and Environmental Effects 2017, 39, 9991006, https://doi.org/10.1080/15567036.2017.1283551.

37. Filibeli, A.; Erden, G.; Gunduz, C. Ultrasonic pre-treatment of wastewater sludge from a meat processing industry. Brazilian Journal of Chemical Engineering 2018, 35, 909-918, https://doi.org/10.1590/01046632.20180353s20170156.

38. Collivignarelli, M.C.; Abbà, A.; Carnevale Miino, M.; Torretta, V. What advanced treatments can Be used to minimize the production of sewage sludge in WWTPs? Applied Sciences 2019, 9, 2650, https://doi.org/10.3390/app9132650.

39. Wei, H.; Gao, B.; Ren, J.; Li, A.; Yang, H. Coagulation/flocculation in dewatering of sludge: A review. Water Res. 2018, 143, 608-631, https://doi.org/10.1016/j.watres.2018.07.029.

40. Anouzla, A.; Abrouki, Y.; Souabi, S.; Safi, M.; Rhbal, H. Colour and COD removal of disperse dye solution by a novel coagulant: application of statistical design for the optimization and regression analysis. J. Hazard. Mater. 2009, 166, 1302-1306, https://doi/org/10.1016/j.jhazmat.2008.12.039.

41. Anouzla, A.:Valorisation des Rejets Liquides du Secteur Sidérurgique: Application au Traitement des Eaux Usées, Editions Universitaires Européennes, 2019.

42. Anouzla, A., Souabi, S.: Treatment of industrial discharges loaded with dyes and surfactant Textile wastewater : characterization, environmental impact and treatment, Scholars' Press, 2020. 